\title{
Alcohol-related risk and harm amongst young offenders aged 11-17
}

\author{
Dorothy Newbury-Birch, Katherine Jackson, Tony Hodgson, Eilish Gilvarry, Paul Cassidy, \\ Simon Coulton, Vicky Ryan, Graeme B. Wilson, Ruth McGovern and Eileen Kaner
}

The authors affiliations can be found at the end of this article.

Received 23 August 2013 Revised 24 October 2014 Accepted 18 December 2014

(c) Dorothy Newbury-Birch, Katherine Jackson,

Tony Hodgson, Eilish Gilvarry, Paul Cassidy, Simon Coulton, Vicky Ryan, Graeme B. Wilson, Ruth McGovern, Eileen Kaner. Published by Emerald Group Publishing Limited. This article is published under the Creative Commons Attribution (CC BY 3.0) licence. Anyone may reproduce, distribute, translate and create derivative works of this article (for both commercial \& noncommercial purposes), subject to full attribution to the original publication and authors. The full terms of this licence may be seen at http://creativecommons.org/ licences/by/3.0/legalcode

\begin{abstract}
Purpose - The purpose of this paper is to examine the prevalence of alcohol use disorders (AUDs) amongst young people in the criminal justice system (CJS) in the North East of England and to compare the ability of the Alcohol Use Disorders Identification Test (AUDIT) to the Youth Justice Board ASSET tool in identifying alcohol-related need in Youth Offending Team (YOT) clients.

Design/methodology/approach - A validated screening tool (AUDIT) was used to identify alcohol-related health risk or harm. Findings from AUDIT were compared with those of the standard criminogenic risk screening tool used in CJS (ASSET). An anonymous cross-sectional questionnaire was administered during a one-month period in 2008. The questionnaires were completed by 11-17-year-old offenders who were in contact with three YOTs, one Youth Offending Institution and one Secure Training Estate.

Findings - In total, 429 questionnaires were completed out of a possible 639 (67 per cent). The majority (81 per cent) of the young offenders were identified as experiencing alcohol-related health risk or harm and 77 per cent scored within a possibly alcohol-dependent range. In total, 77 (30 per cent) of young people completing both assessments were identified as having an AUD by AUDIT but not identified as needing alcohol-related treatment using ASSET.

Research limitations/implications - This research was confined to one geographical area of England, however, the results show that even in this area of high drinking by young people the levels of AUDs amongst young people in the CJS are very high.

Social implications - There are major social implications to this research. It is imperative for changes to be made to the care pathways in place in the UK for young people coming through the CJS with alcohol-related issues.

Originality/value - This paper adds to the evidence base by using well-validated tools to measure alcohol use amongst young people in the CJS in the UK.

Keywords Criminal justice system, Prison, Alcohol, Substance abuse, Young offenders,

Youth offending service

Paper type Research paper

\section{Introduction}

Adolescents in England are amongst the heaviest drinkers in Europe (Hibbell et al., 2012). The percentage of adolescents who have ever had an alcoholic drink in England increases with age from 12 per cent of those aged 11 to 74 per cent of those aged 15, and the prevalence of drinking in the last week rises from 1 per cent of those aged 11 to 25 per cent of those aged 15 (Fuller et al. , 2013). Although the proportion of adolescents in England aged between 11 and 15 years who report that they have ever drunk alcohol decreased from 54 to 43 per cent between 2007 and 2012, the mean amount in those that drank increased from 10.4 standard drink units per week in 2011 to 12.5 units per week in 2012 (Fuller et al., 2013). This clearly shows that drinking increases over adolescence, but that this is not immutable, with changes in trends over time and with age. The North East of England has been shown to have the highest rates of
\end{abstract}


alcohol misuse by adolescents in England, with 51 per cent of 11-15-year-olds reporting having ever drunk alcohol (Fuller et al., 2013). This compares to 48 per cent in the South East, 46 per cent in the North West and 31 per cent in London (Fuller et al., 2013). Further, the mean alcohol consumption in the previous week for adolescents in England is highest in the North East and North West (15.7 units per week) compared to the South East (11.0) and London (9.4 units) (Fuller et al., 2013).

The impact of alcohol on the development and behaviour of adolescents has been well researched in early (Zucker et al., 2009), middle (Windle et al., 2009) and late adolescence (Brown et al., 2009). It is now well known that adolescents are much more vulnerable than adults to the adverse effects of alcohol, due to a range of physical and psycho-social factors which often interact (Newbury-Birch et al., 2009a; Marshall, 2014). These adverse effects include: physiological factors resulting from a typically lower body mass and less efficient metabolism of alcohol (Windle et al., 2009; Zucker et al., 2009); neurological factors due to changes that occur in the developing adolescent brain after alcohol exposure (Windle et al., 2009; Squeglia et al., 2012); cognitive factors due to psychoactive effects of alcohol which impair judgement and increase the likelihood of accidents and trauma (Rodham et al., 2006); and social factors which arise from a typically high-intensity drinking pattern (often called "binge drinking") which leads to intoxication and risk-taking behaviour (MacArthur et al., 2012). The latter are compounded by the fact that adolescents have less experience of dealing with the effects of alcohol than adults (Murgraff et al., 1999), and they have fewer financial resources to help buffer the social and environmental risks that result from drinking alcohol (Brown et al., 2009).

The Chief Medical Officer for England has provided recommendations on alcohol consumption in young people (Donaldson, 2009) based on an evidence review of the risks and harms of alcohol to young people (Newbury-Birch et al., 2009a). The recommendations state that children should abstain from alcohol before the age of 15 and those aged 15-17 are advised not to drink, but if they do drink it should be no more three to four units and two to three units per week in males and females, respectively, on no more than one day per week (Donaldson, 2009) which equates to adult daily drinking recommendations.

A particular group of adolescents at risk due to their drinking is young offenders (Kennedy, 2013). Evidence shows that drinking amongst adolescents under the age of 18 years, especially frequent drinking, is associated with criminal and disorderly behaviour (Fuller et al., 2013). Alcohol consumption amongst adolescents aged ten to 17 years is estimated to be responsible for 80,640 violent offences per year (Budd et al., 2005) and to cost in excess of $£ 5$ million per year for criminal activity to the Criminal Justice System (CJS) (Bellis et al., 2007). Moreover, adolescents who drink are more likely than non-drinkers to be both perpetrators and victims of violence (Newburn and Shiner, 2001). These data have culminated in a joint health and criminal justice policy focusing on identifying and tackling youth drinking and social disorder in the UK (HM Government, 2009a, b).

In the UK, higher rates of alcohol misuse have been found at various stages in the CJS for adults, compared to the 20-30 per cent observed in primary care populations (Funk et al., 2005; Coulton et al., 2012), with around two-thirds of men and women having established problematic alcohol use. This encompasses those arrested at police stations (Brown et al., 2010), within probation settings (Newbury-Birch et al., 2009b; Orr et al., 2015) and those in prison (Graham et al., 2012; Fazel et al., 2006; Newbury-Birch et al., 2009b). High rates are also found among adolescents within the CJS with a study of 16-20-year-olds in the prison system in England and Wales reporting that 62 per cent of males and 13 per cent of females on remand and 70 per cent of males and 51 per cent of females of those sentenced experienced an Alcohol Use Disorder (AUD) using a cut-off of eight on the ten question Alcohol Use Disorders Identification Test (AUDIT) (Lader et al., 2000).

\section{Identifying alcohol-related risk and harm in adolescents}

The AUDIT is a screening tool that was developed to help practitioners identify people who drink excessively. The AUDIT consists of ten questions about alcohol consumption, alcohol dependence and alcohol-related problems. Shortened versions have also been validated for use.

PAGE $76 \quad$ INTERNATIONAL JOURNAL OF PRISONER HEALTH $\mid$ VOL. 11 NO. 22015 
In adult populations, the AUDIT ten question tool is regarded to be the "gold standard" screening tool for identifying alcohol-related risk or harm (Saunders et al., 1993). At a cut-off point of eight (out of a possible total score of 40 ), it has a sensitivity and specificity of identifying alcohol-related risk or harm of 92 and 94 per cent, respectively (Saunders et al., 1993). A further positive feature of AUDIT is that it can distinguish between different types of alcohol-related risk: hazardous drinking (scores 8-15) which identifies an amount or pattern of drinking that increases the risk of physical or psychological problems; harmful drinking (scores 16-19) which is defined by the presence of physical or psychological symptoms; and probable alcohol dependence (scores 20+) which is a cluster of physiological, behavioural and cognitive phenomena conforming to the "alcohol dependence syndrome" (Babor et al., 1989). Occurrence of any of these three drinking profiles is called an AUD (Saunders et al., 1993).

A systematic review commissioned by the English National Institute for Health and Clinical Excellence examined the validity of alcohol screening in a wide range of settings for both adolescents (age ten to 17 years) and adults (aged over 18 years). This review found that questionnaires performed better than blood markers or breath alcohol concentration for adults and adolescents (Jackson et al., 2009). AUDIT has been found to have greater sensitivity and specificity for identifying likely AUDs than other youth-focused alcohol screening questionnaires (Cook et al., 2005). Thus it is currently regarded as the best alcohol screening tool available for adolescents (Cook et al., 2005). In adolescent populations, AUDIT sensitivities have ranged from 54 to 87 per cent, specificities from 65 to 97 per cent. Optimal scores for identifying likely AUDs using the ten question AUDIT range from two to ten (Clark and Moss, 2010). Across a 14-18-year-old age range, likely hazardous or harmful drinking has been identified at an AUDIT score of $2+$ and probable dependent drinking at an AUDIT score of 3+ with sensitivity and specificity values of 83 and 93 per cent, respectively (Knight et al., 2003). These are the adolescent scores used for the present study.

\section{The ASSET tool}

ASSET is a standardised assessment tool, developed within the CJS in England and Wales, which aims to identify the underlying causes of a young person's offending behaviour and to plan appropriate interventions (Youth Justice Board, 2006b). It is often used on multiple occasions to help measure changes in young offenders' health and social needs and the risk of reoffending over time. ASSET has been used with all young offenders in England and Wales since 2000 and it examines 12 dynamic risk factors: living arrangements; family and personal relationships; education, training and employment; neighbourhood; lifestyle; substance use; physical health; emotional health; perception of self and others; thinking and behaviour; attitudes to offending; and motivation to change. The extent to which each section is associated with the likelihood of further offending is rated on a 0-4 scale (Youth Justice Board, 2006b).

The current research recorded the substance misuse section of ASSET (section 6) which looks at alcohol misuse as well as other drug misuse and includes questions on whether the young person has ever used, or recently used a variety of substances including alcohol. It also looks at the age of first misuse and whether the substance is linked to the young person's offending (Youth Justice Board, 2006a, b). A score of two or more indicates referral to colleagues who specialise in assessment and intervention to ameliorate substance use. This work is often conducted within the secure estate (National Treatment Agency for Substance Misuse, 2012) or Youth Offending Team (YOT) but can occur in liaison with local adolescent substance misuse services (Youth Justice Board, 2006a).

There is however a lack of data on alcohol-related risk or harm in younger adolescents (aged 11-14). Moreover, there is relatively little research conducted in the CJS with young drinkers. The purpose of this present study was to identify alcohol-related risk or harm in the full age range of adolescents in contact with the CJS and to include both community-based and institutional settings. The study sought to compare the risk profile obtained via AUDIT, using both the adult and the suggested adolescent cut-offs, with the standard criminogenic risk assessment tool used in the CJS with young offenders (ASSET). The purpose of this comparison is to determine the sensitivity of identifying likely AUDs using the ASSET. The study will also compare the prevalence and severity of AUD by offence type. 


\section{Methods}

\section{Sample}

The study was based in community-based YOTs and secure establishment institutions in the North East of England. All 11 YOTs and all three secure establishments were approached to be involved in the study. Three YOTs and the two secure establishments (one Secure Training Estate and one Youth Offending Institution) agreed to be involved. The reason for non-participation in the study was workload. Approval for the study was obtained from the local Youth Justice Board (YJB) and the prison service. The methods in this study are identical to those used in our previous study of alcohol prevalence rates in adult offenders in the North East of England (Newbury-Birch et al., 2009b).

A convenience sample of staff from YOTs and secure estates recruited young offenders into the study during a one-month period in 2008. Staff administered questionnaire that included no identifiable information from the young person.

Cross-sectional designs entail the collection of data of a large sample and at a single point in time in order to collect a body of data in connection with multiple variables which can be examined to detect patterns of association (Bryman, 2004). It was agreed with participating staff that collecting data over a one-month period would encourage maximum participation in questionnaire administration without being too burdensome in the longer-term. For the secure establishments this was March 2008 and for the YOTs September 2008. Due to staffing constraints at the sites it was not possible to carry out the research in the same time period. Questionnaires were administered by criminal justice staff that had been trained by the research team. This training included how to gather informed consent from young people and how to administer and score the AUDIT tool as well as gather the information required to complete the questionnaire. Criminal justice staff were involved to enable explanation of the questions when needed by the young people.

\section{Measures}

AUDIT. In this present study both the adult cut-off ranges of 8-15 (hazardous drinking) 16-19 (harmful drinking) and 20+ (probable dependence) (Saunders et al., 1993) and the adolescent cut-off ranges of $2+$ (hazardous/harmful drinking) and $3+$ (probable dependence) previously used by Knight et al. (2003) were used.

ASSET. The ASSET score currently recorded by the YOT/secure estate was used within this study. A score of 2 or more (which indicates referral for specialist intervention) was used as the cut-off for identification of alcohol-related risk.

\section{Study questionnaire}

A one page questionnaire was developed which consisted of: the ten items of AUDIT; demographic data including age (at time of completing the questionnaire) and gender. Boxes were included for the staff member to record the young person's ethnicity; offence and sentence (no categories were given for this). A visual aid of alcoholic drinks and related units was included. The adolescents ASSET score relating to substance misuse (ASSET section 6) was added by the staff member onto the questionnaire.

\section{Procedures}

All staff in the participating sites that came into contact with the young offenders were asked to complete a questionnaire with every consenting young offender they engaged with during the study period. Staff asked the questions and completed the questionnaire with the respondents' answers. Files were marked to ensure that adolescents were only asked once to participate in the study. However there is a small possibility that a young offender asked in the YOT could have been asked in the secure estate also. The inclusion criterion was all adolescents in the age range who had not already completed the questionnaire (as marked on their file). In accordance with ethical guidelines (Shaw et al., 2011), the adolescents were informed by the staff at the sites that 
their participation was voluntary and would not have any effect on their usual care. By returning the anonymous questionnaire filled in, participants were told that they were deemed to have given consent to participate in the study. Completed questionnaires were stored securely in each of the sites and were collected regularly by members of the research team.

\section{Analysis plan}

The data were subsequently entered into SPSS. Analysis was undertaken using the statistical software package PASW 18 (SPSS Inc.). Offences were categorised as either violent (assaults, robbery, rape, possession of offensive weapons or causing death) or non-violent (affray, arson, burglary, criminal damage, drugs, motor offences, theft, trespass, perverting the course of justice and public order) as has been used in previous criminal justice studies (Sherman et al. , 2007). The statistical analysis was primarily descriptive and focused on the prevalence of alcohol misuse; AUDIT scores less than 2 for low-risk drinkers, 2 for hazardous or harmful drinkers and 3 or more for probably dependent, and their relationship to offence type and ASSET score for substance misuse (a score of 2 or more). Where appropriate, comparisons were made across different demographic groups of adolescents. $\chi^{2}$ statistics were used to assess categorical data. We explored the sensitivity, the number of true positive cases identified, and specificity, the number true negative cases identified, of ASSET score of 2 or more vs AUDIT score of 2 or more as an indicator of AUDs and AUDIT score of 2 or more vs. Binge drinking derived from question three of the AUDIT which relates to binge drinking (How often do you have six or more standard drinks on one occasion) was used (Saunders et al., 1993).

\section{Results \\ Sample}

In total, 429 questionnaires were completed with young offenders by the YOTs and secure establishments during the study time period. In total, 18 of these questionnaires were excluded (12 who were aged 18 or over; six with no age given). Of the 411 that were included in the analysis, 227 (55 per cent) were from the YOT and 184 (45 per cent) from secure accommodation. The response rate was 67 per cent (97 per cent secure accommodation, $n=189 ; 53$ per cent YOTs, $n=240 / 450)$.

\section{Demographics}

In total, 85 per cent of participants were male $(n=349)$ and 15 per cent female $(n=60)$. Two questionnaires did not have gender recorded. This is a higher proportion of males: females than the proportion of young male offenders recorded for the North East in the CJS in the region in 2008-2009 (75 per cent male) (Youth Justice Board, 2010). The majority of the females were from the YOT setting (93 per cent). In total, 97 per cent who gave their ethnicity described themselves as white or white British which is comparable with the general population in the North East of England at the same time point (Office for National Statistics, 2011).

The age range of participants was 11-17 years with 6 per cent $(n=26)$ aged between 11 and 13; 25 per cent $(n=100)$ aged 14 or 15 and 69 per cent (283) aged 16-17 (two did not give age).

\section{AUDIT results}

In total, 25 of the 411 (6 per cent) respondents did not complete the AUDIT fully, therefore 386 (male 329; 85 per cent; females 55; 14 per cent) individuals with an AUDIT score and age recorded were included in the analysis. The mean age of all included was 15.9 SD 1.2; median 16 (range 11-17).

In total, 16 per cent reported that they had not drunk in the last year (50 per cent $n=12 / 24$ of those aged between 11 and 13; 24 per cent $n=23 / 95$ of those aged 14-15 and 9 per cent $n=25 / 267$ of those aged 16-17). Those with a likely AUD of the highest severity (probably dependent) were high in all age groups (33 per cent $n=8 / 24$ of those aged between 11 and 13; 62 per cent $n=59 / 95$ of those aged 14-15; 86 per cent $n=229 / 267$ of those aged between 16 and 17 (Table I). 


\begin{tabular}{|c|c|c|c|c|c|c|c|c|c|c|}
\hline \multirow[b]{2}{*}{ Age } & \multicolumn{2}{|c|}{ Abstainers } & \multicolumn{2}{|c|}{ Low risk } & \multicolumn{2}{|c|}{ Hazardous/harmful } & \multicolumn{2}{|c|}{ Probably dependent } & \multicolumn{2}{|c|}{ Total AUD } \\
\hline & $n$ & $\%$ & $n$ & $\%$ & $n$ & $\%$ & $n$ & $\%$ & $n$ & $\%$ \\
\hline $11-13(n=24)$ & 12 & 50.0 & 1 & 4.2 & 3 & 12.5 & 8 & 33.3 & 11 & 45.8 \\
\hline $14-15(n=95)$ & 23 & 24.2 & 9 & 9.5 & 4 & 4.2 & 59 & 62.1 & 63 & 66.3 \\
\hline $16-17(n=267)$ & 25 & 9.4 & 4 & 1.5 & 9 & 3.4 & 229 & 85.8 & 238 & 89.1 \\
\hline Total $(n=386)$ & 60 & 15.5 & 14 & 3.6 & 16 & 4.1 & 296 & 76.7 & 312 & 80.8 \\
\hline
\end{tabular}

The mean AUDIT score was 13.3 (SD 10.6; median 12; Cl 3-21). When the non-drinkers were removed from the sample the mean AUDIT score was 15.8 (SD 9.7; median 14; Cl 8-23).

Adolescent AUDIT cut-offs. Using adolescent cut-offs, 81 per cent of participants scored 2+ on the AUDIT which identifies likelihood of an AUD. In total, 77 per cent scored 3+ on the AUDIT which identifies a likely AUD of greater severity (probable alcohol dependence).

Adult AUDIT cut-offs. Using adult cut-offs 64 per cent of participants scored 8+ on the AUDIT which identifies likelihood of AUD (22 per cent hazardous; 12 per cent harmful; 30 per cent probable alcohol dependence).

Further to this, the percentage of adolescents who were likely to have an AUD increased from 46 per cent of those aged 11-13 to 66 per cent of those aged 14-15 to 89 per cent of those aged 16 or above $\left(\chi^{2} 43.78 ; \mathrm{df}=2 ; p=<0.001\right)$. The full profile of responses (number and percentage) to the ten AUDIT questions is displayed in Table II.

\section{Offence type}

In total, 309 (75 per cent) questionnaires had data recorded relating to both offence type and AUDIT score. Significantly more offences were classed as non-violent offences ( $n=170,55$ per cent) than violent offences $\left(n=139,45\right.$ per cent; $\left.\chi^{2} 5.825 ; \mathrm{df}=1 ; p=0.01\right)$ (Table III).

In total, 84 per cent of the adolescents convicted of a violent offence scored positive for an AUD (score of $2+$ ) compared to 83 per cent of those convicted of a non-violent offence. This difference was not statistically significant $\left(\chi^{2}<0.0001 ; \mathrm{df}=1 ; p=0.9866\right)$.

However, significantly more individuals convicted of a violent offence (38 per cent) scored as probable dependent (3+) compared to those with a non-violent offence (24 per cent) $\chi^{2} 6.094$; $\mathrm{df}=1 ; p=0.0136)$. Furthermore a significant difference was observed in mean AUDIT score between violent and non-violent offenders; 14.92 vs $12.57(p=0.03)$. All of those convicted of an assault against a police officer, 78 per cent of those convicted of all other assaults; 81 per cent of those convicted of robberies; 92 per cent of those convicted of use of an offensive weapon; 50 per cent of those convicted of rapes and 78 per cent of those convicted of violence-related public order offences scored in the probable dependent range of an AUD for adolescents (3+) using the AUDIT.

\section{ASSET scores}

Of the 429 questionnaires completed, 259 (60 per cent) had both an AUDIT and an ASSET score for substance misuse available. In total, 24 per cent scored zero on ASSET ( $n=63)$; 23 per cent had a score of one $(n=62)$; 24 per cent had a score of two $(n=65)$; 21 per cent had a score of three $(n=56)$ and 8 per cent had a score of four $(n=20)$. Overall 30 per cent $(n=77)$ of the adolescents identified by AUDIT as at risk of an AUD were not identified as being at risk due to their substance misuse using ASSET (score 2+) alone. The ASSET has relatively low sensitivity (0.626) and higher specificity (0.793) (Table IV) at identifying AUDIT positives compared to 


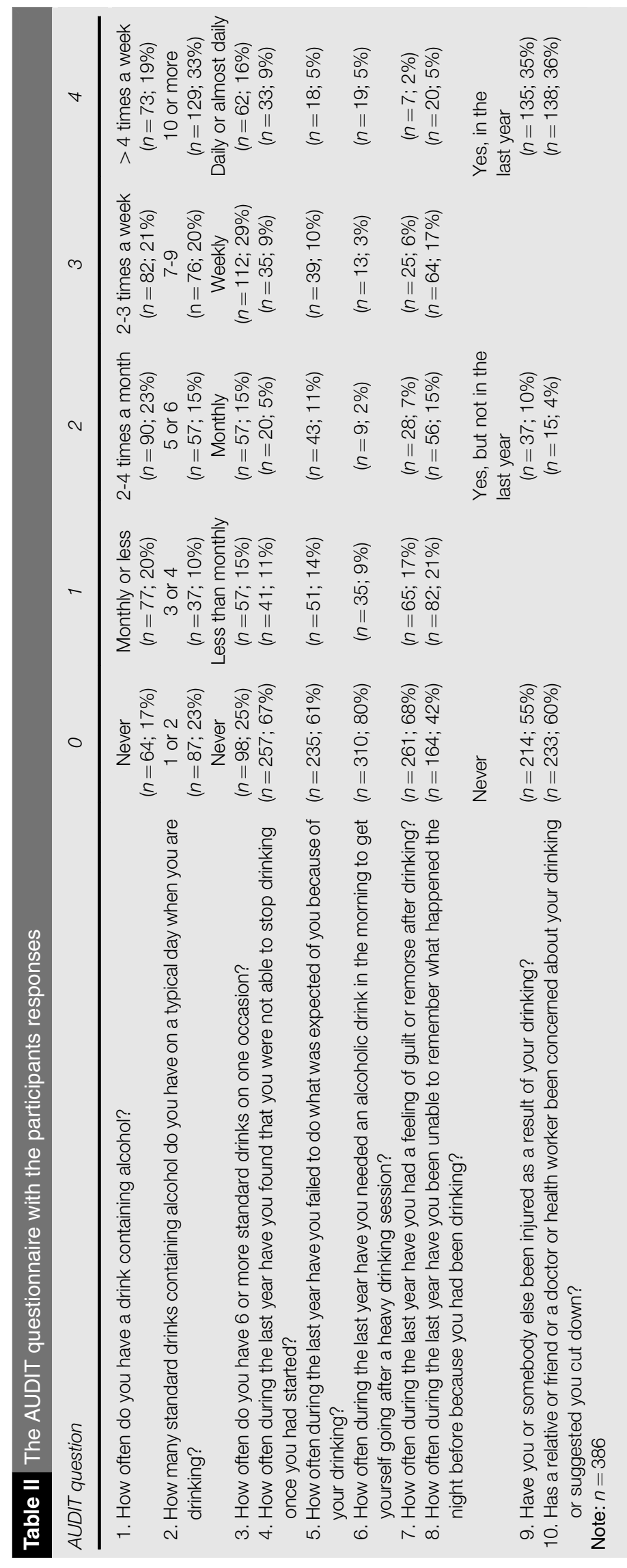


Table III Offence types of included sample

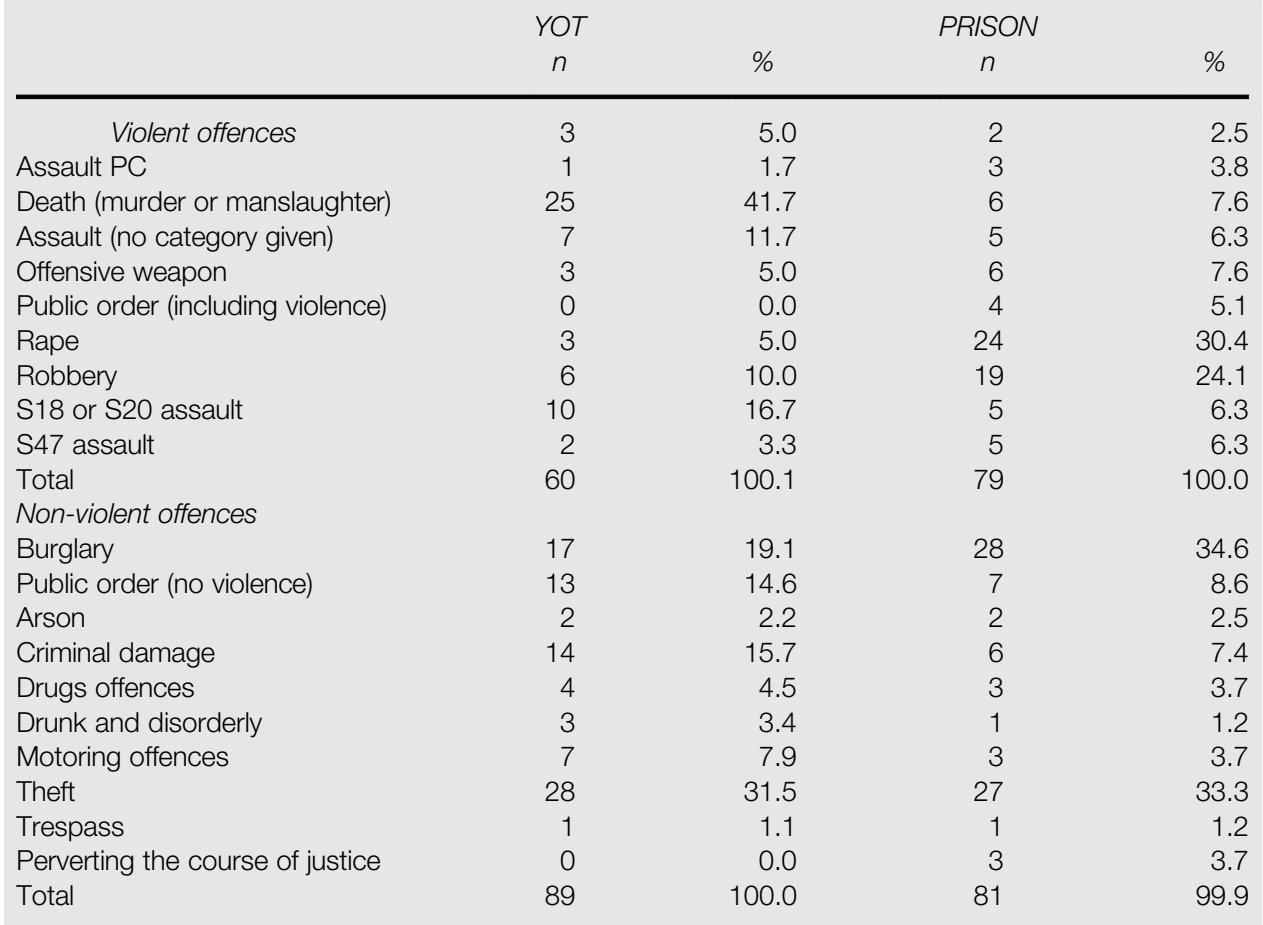

\section{Table IV Sensitivity and specificity of ASSET score of 2 or more in identifying those with} AUD, AUDIT score 2 or more

Value $(95 \% \mathrm{Cl})$

Sensitivity

$0.626(0.558 ; 0.689)$

Specificity

$0.793(0.665 ; 0.880)$

question 3 of the AUDIT (How often do you have six or more standard drinks on one occasion), which shows high levels of sensitivity (0.917) and specificity (0.987) (Table V). This indicates that this question alone has advantages over the ASSET as a screening tool for identifying likely AUDs in this group of individuals.

\section{Discussion}

This cross-sectional study found high rates of drinking amongst adolescents attending youth justice settings in the North East of England and a high prevalence of likely AUDs as indicated using the AUDIT. In total, 81 per cent of the young offenders in this study were identified as likely having an AUD using a cut-off of $2+$ on AUDIT and the likely AUD rate was also higher than that

Table V Sensitivity and specific of AUDIT score of 2 or more identifying any binge consumption

Value $(95 \% \mathrm{Cl})$

Sensitivity

$0.917(0.883 ; 0.942)$

Specificity 0.987 (0.928; 0.998) 
reported for adults in the CJS in the North East of England (63 per cent) (Newbury-Birch et al., 2009b). Moreover, 77 per cent of young offenders were identified as probably dependent (cut-off of 3+); a pattern of use associated with high levels of health and social risk. This study also showed that the percentage of adolescents in youth justice settings who were likely to have an AUD increased by age from aged 11 to 17 as in the general population, however, at much higher rates at all ages.

The general population rate for likely AUD in adults in England and Wales is 26 per cent (Drummond et al., 2004). Indeed, the more conservative analysis (using adult cut-offs of 8+) of alcohol-related risk or harm would have indicated that 22 per cent of adolescents were likely to be drinking hazardously and 42 per cent likely to be drinking in the harmful or probable alcohol-dependent range. These compare to general adult population rates of 23 per cent in the likely hazardous or harmful range and 4 per cent in the probable dependent range (Drummond et al., 2004). Furthermore, although numbers were small, the results showed that nearly half of those aged 11-13 were categorised as likely having an AUD with a third of this age group being classified as probably dependent to alcohol. This information is vital for staff training to deal with severe issues with such a young age group.

Significantly more adolescents convicted of a violent offence (compared to a non-violent offence) scored within the probable alcohol-dependent range. The present study further showed that 30 per cent of all adolescents attending the YOT identified by AUDIT as likely to have an AUD were not identified as having an alcohol-related need using the ASSET tool. The ASSET is completed by workers who are not specialists in identifying alcohol and substance misuse and the primary intention of ASSET screening is to identify factors linked to offending behaviour (either disclosed by the young person or known to the YOT officer from previously recorded information). Thus it is possible that both the limited skill set of youth justice staff in identifying alcohol-related risk or harm and the criminogenic focus of ASSET may be limiting factors for the full recognition of alcohol-related problems in this setting as has been found elsewhere in the CJS (Newbury-Birch et al., 2009b). Nevertheless, this study shows that even adding a single question from AUDIT (question 3) to the ASSET might significantly increase the ability of youth justice professionals to identify alcohol-related risk or harm in young offenders. However, the broader issue of whether young offenders are willing to disclose details of a behaviour that might be linked to offending to youth justice staff needs to be explored in more depth.

There were a number of limitations to the data presented in this paper. The initial response from the YOTs was low with only three out of a possible 11 YOTs agreeing to participate in the study, impacting upon the representativeness of the sample of young people recruited. It is possible that a small number of young offenders were asked at both a YOT and within the secure estate. Moreover, the research was only carried out in one geographical area of England and therefore the results may not be indicative of the whole country. In addition, the administration of questionnaires by youth justice staff may have influenced young offenders reporting of their drinking behaviour. However, any suggestion that the young offenders may have been inclined to under-report so as not to prejudice their future management in the CJS seems to be contradicted by the high rates of drinking and likely AUDs reported. Furthermore, the ASSET substance section includes alcohol and drugs so it is not possible to extrapolate data relating only to alcohol, however, this is the current method of identifying young offenders with alcohol issues in England and Wales. Lastly, the high response rates achieved during routine youth justice practice, including 97 per cent of all adolescents in the secure estate, suggests that a realistic reflection of young offender behaviour was achieved. Workload was the reason given by staff in the YOTs for why some questionnaires were not completed.

A key issue identified in this study related to the accurate measurement of alcohol-related risk and harm in young offenders. Although the AUDIT has been identified as being the best tool to use with adolescents (Cook et al., 2005), there needs to be further investigation of the validity and reliability of the tool with younger age groups, particularly in a UK context (Reinert and Allen, 2007). In particular, it is important to investigate whether all the questions on AUDIT have the same meaning (and signify the same categories of risk, harm and dependence) for adolescents as they do for adults. In particular, the proportion of young offenders who showed probable signs of alcohol dependence (75 per cent) in our sample was extremely high. Since adolescents have 
different levels of understanding compared to adults, and since young offenders often have lower levels of educational attainment than non-offenders, it is possible that questions relating to physical or psychological dependence may have been misinterpreted. Furthermore, behaviour that is clearly indicative of alcohol dependence in adults (such as drinking alcohol in the morning to prevent withdrawal effects) may not have the same meaning for adolescents. Nevertheless, regardless of whether drinking in the morning occurs to prevent alcohol withdrawal or for an entirely different reason still indicates a high degree of alcohol-related risk for adolescents and possibly for recipients of alcohol-related crime and disorder.

A further concern was the high levels of likely AUDs at all ages; with rates rising from 46 per cent in 11-13-year-olds to 89 per cent in 16-17-year-olds. This present study suggests that alcoholrelated risk or harm identified by the AUDIT tool in around 30 per cent of young offenders is not correctly identified using the current systems and procedures in youth offending organisations. This has significant implications for the YJB since the ASSET tool may be failing to identify significant numbers of young offenders with alcohol-related problems using a tool that measures both alcohol and drug use. In addition to compromising the well-being of young offenders, this is an important workload issue. Problematic drinking behaviour is highly likely to increase the risk of future offending behaviour. More research needs to be carried out in the youth justice system in order to identify the best alcohol screening and assessment tool for use with different age groups of young offenders who drink. Professionals in the youth justice system need more training in alcohol-related issues so that they are more clearly aware of the link between alcohol and crime and better able to identify risk of AUDs. Furthermore, there is a need for alcohol treatment services which are specifically geared towards adolescents. All young people deserve access to the best possible care in order to give them the best chance in life and a valuable opportunity is being missed for the many young offenders who come into contact with the youth justice system.

\section{References}

Babor, T.F., De La Fuente, J.R., Saunders, J. and Grant, M. (1989), AUDIT, The Alcohol Use Disorders Identification Test, Guidelines for Use in Primary Health Care, World Health Organization, Geneva.

Bellis, M., Hughes, K., Morleo, M., Tocque, K., Hughes, S., Allen, T. and Harrison, D. (2007), Alcohol and Schools - Addendum on Additional Economic Evidence, A Review of the Effectiveness and Cost-effectiveness of Interventions Delivered in Primary and Secondary Schools to Prevent and/or Reduce Alcohol Use by Young People Under 18 Years Old, Liverpool.

Brown, N., Newbury-Birch, D., McGovern, R., Phinn, E. and Kaner, E. (2010), "Alcohol screening and brief intervention in a policing context: a mixed methods feasibility study", Drug \& Alcohol Review, Vol. 29 No. 6, pp. 647-54.

Brown, S., McGue, M., Maggs, J., Schulenberg, J., Hingson, R., Swartzwelder, S., Martin, C., Chung, T., Tapert, S., Sher, K., Winters, K., Lowman, C. and Murphy, S. (2009), "Underage alcohol use summary of developmental processes and mechanisms: ages 16-20", Alcohol Research and Health, Vol. 32 No. 1, pp. 41-52.

Bryman, A. (2004), Social Research Methods, 2nd ed., Oxford University Press, Hampshire.

Budd, T., Sharp, C. and Mayhew, P. (2005), Offending in England and Wales: First Results from the 2003 Crime and Justice Survey, Home Office Research Study 275, Home Office Research Development and Statistics Directorate, London.

Clark, D.B. and Moss, H.B. (2010), "Providing alcohol-related screening and brief interventions to adolescents through health care systems: obstacles and solutions", Public Library of Science (PLoS) Medicine, Vol. 7 No. 3, p. e1000214.

Cook, R.L., Chung, T., Kelly, T.M. and Clark, D.B. (2005), "Alcohol screening in young persons attending a sexually transmitted disease clinic”, Journal of General Internal Medicine, Vol. 20 No. 1, pp. 1-6.

Coulton, S., Newbury-Birch, D., Cassidy, P., Dale, V., Deluca, P., Gilvarry, E., Godfrey, C., Heather, N., Kaner, E., Oyefeso, A., Parrott, S., Phillips, T., Shepherd, J. and Drummond, C. (2012), "Screening for alcohol use in criminal justice settings: an exploratory study", Alcohol and Alcoholism, e-pub ahead of publication Vol. 47 No. 4, pp. 423-7.

Donaldson, L. (2009), Guidance on the Consumption of Alcohol by Children and Young People, London. 
Drummond, C., Oyefeso, A., Phillips, T., Cheeta, S., Deluca, P., Perryman, K., Winfield, H., Jenner, J., Cobain, K., Galea, S., Saunders, V., Fuller, T., Pappalardo, D., Baker, O. and Christoupoulos, A. (2004), Alcohol Needs Assessment Research Project (ANARP), The 2004 National Needs Assessment for England, Department of Health, London.

Fazel, S., Bains, P. and Doll, H. (2006), "Substance abuse and dependence in prisoners: a systematic review", Addiction, Vol. 101 No. 2, pp. 181-91.

Fuller, E., Henderson, H., Nass, L., Payne, C., Phelps, A. and Ryley, A. (2013), Smoking, Drinking and Drug Use Among Young People in England in 2012, Health and Social Care Information Centre, L.S., London.

Funk, M., Wutzke, S., Kaner, E., Anderson, P., Pas, L., McCormick, R., Gual, A., Barfod, S., Saunders, J. and on behalf of the World Health Organization (WHO) Brief Intervention Study Group (2005), "A multicountry controlled trial of strategies to promote dissemination and implementation of brief alcohol intervention in primary health care: findings of a World Health Organization collaborative study", Journal of Studies on Alcohol, Vol. 66 No. 3, pp. 379-88.

Graham, L., Parkes, T., McAuley, A. and Doi, L. (2012), Alcohol Problems in the Criminal Justice System: An Opportunity for Intervention, World Health Organization, Copenhagan.

Hibbell, B., Guttormsson, U., Ahlström, S., Balakireva, O., Bjarnason, T., Kokkevi, A. and Kraus, L. (2012), "The 2011 ESPAD report: substance use among students in 36 European countries", The Swedish Council for information on Alcohol and other Drugs (CAN), Stockholm.

HM Government (2009a), Healthy Children, Safer Communities, HM Government, London.

HM Government (2009b), Improving Health, Supporting Justice, HM Government, London.

Jackson, R., Johnson, M., Campbell, F., Messina, J., Guillaume, L., Purshouse, R., Latimer, N., Rafia, R. and Meier, P. (2009), Screening and Brief Interventions: Effectiveness Review to the National Institute for Health \& Clinical Excellence, Sheffield.

Kennedy, E. (2013), Children and Young People in Custody 2012-13: An Analysis of 15-18-Year-Olds' Perceptions of their Experiences in Young Offender Institutions, Crown Copyright, London.

Knight, J., Sherritt, L., Harris, S., Gates, E. and Chang, G. (2003), "Validity of brief alcohol screening tests among adolescents: a comparison of the AUDIT, POSIT, CAGE and CRAFFT", Alcoholism: Clinical and Experimental Research, Vol. 27 No. 1, pp. 67-73.

Lader, D., Singleton, N. and Meltzer, H. (2000), Psychiatric Morbidity among Young Offenders in England and Wales, Office for National Statistics, London.

MacArthur, G., Smith, M., Melotti, R., Heron, J., Macleod, J., Hickman, M.Kipping, R., Campbell, R. and Lewis, G. (2012), "Patterns of alcohol use and multiple risk behaviour by gender during early and late adolescence: the ALSPAC cohort", Journal of Public Health, Vol. 34 No. S1, pp. i20-i30.

Marshall, E. (2014), "Adolescent alcohol use: risks and consequences", Alcohol \& Alcoholism, Vol. 49 No. 2, pp. 160-4.

Murgraff, V., Parrott, A. and Bennett, P. (1999), "Risky single-occasion drinking amongst young people definition, correlates, policy, and intervention: a board overview of research findings", Alcohol \& Alcoholism, Vol. 34 No. 1, pp. 3-14.

National Treatment Agency for Substance Misuse (2012), Substance Misuse Interventions within the Young People's Secure Estate: Guiding Principles for Transferring Commissioning Responsibility from the YJB to Local Partnership Areas, National Treatment Agency for Substance Misuse, London.

Newburn, T. and Shiner, M. (2001), Teenage Kicks? Young People and Alcohol: A Review of the Literature, York Joseph Rowntree Foundation, York.

Newbury-Birch, D., Harrison, B., Brown, N. and Kaner, E. (2009b), "Sloshed and Sentenced: a prevalence study of alcohol use disorders amongst offenders in the North East of England", International Journal of Prisoner Health, Vol. 5 No. 4, pp. 201-11.

Newbury-Birch, D., Gilvarry, E., McArdle, P., Stewart, S., Walker, J., Lock, C., Avery, L., Jackson, K., Beyer, F., Brown, N., McGovern, R. and Kaner, E. (2009a) "The impact of alcohol consumption on young people: a review of reviews", Department of Children, Schools and Families, London, Report no. DCSF-RR067.

Office for National Statistics (2011), 2010 Census: Key Statistics for England and Wales, Office for National Statistics, London. 
Orr, K., McAuley, A., Graham, L. and McCoard, S. (2015), "Applying and alcohol brief intervention (ABI) model to the community justice setting: learning from a pilot project”, Criminology and Criminal Justice, Vol. 15 No. 1 , pp. 83-101.

Reinert, D. and Allen, J. (2007), "The alcohol use disorder identification test: an update of research findings", Alcoholism: Clinical and Experimental Research, Vol. 31 No. 2, pp. 185-99.

Rodham, K., Brewer, H., Mistral, W. and Stallard, P. (2006), "Adolescents' perception of risk and challenge: a qualitative study”, Journal of Adolescence, Vol. 29 No. 2, pp. 261-72.

Saunders, J.B., Aasland, O.G., Babor, T.F., De La Fuente, J.R. and Grant, M. (1993), "Development of the alcohol use disorders identification test (AUDIT): WHO collaborative project on early detection of persons with harmful alcohol consumption", Addiction, Vol. 88 No. 6, pp. 791-804.

Shaw, C., Brady, L. and Davey, C. (2011), Guidelines for Research with Children and Young People, NCSBR, London.

Sherman, L., Strang, H., Barnes, G., Bennett, S., Angel, C., Newbury-Birch, D., Woods, D. and Gill, C. (2007), "Restorative justice: the evidence", available at: www.sas.upenn.edu/jerrylee/RJ_full_report.pdf (accessed 22 September 2014).

Squeglia, L.M., Pulido, C., Wetherill, R.R., Jacobus, J., Brown, G.G. and Tapert, S.F. (2012), "Brain response to working memory over three years of adolescence: influence of initiating heavy drinking", Journal of Studies on Alcohol and Drugs, Vol. 73 No. 5, pp. 749-60.

Windle, M., Spear, L., Fuligni, A., Angold, A., Brown, J., Pine, D., Smith, G., Giedd, J. and Dahl, R. (2009), "Transitions into underage and problem drinking summary of developmental processes and mechanisms: ages 10-15", Alcohol Research and Health, Vol. 32 No. 1, pp. 30-40.

Youth Justice Board (2006a), Yot Substance Misuse Worker Guidance: Intergrating Youth Justice Provision and Substance Misuse Treatment, YJB, London.

Youth Justice Board (2006b), “Asset - young offender assessment profile London”, available at: www.justice. gov.uk/youth-justice/assessment/asset-young-offender-assessment-profile (accessed 22 September 2014).

Youth Justice Board (2010), Youth Justice Annual Workload Data 2008/09, Youth Justice Board, London.

Zucker, R., Donovan, J., Masten, A., Mattison, M. and Moss, H. (2009), "Developmental perspective on underage alcohol use. Developmental processes and mechanisms 0-10", Alcohol Research and Health, Vol. 32 No. 1, pp. 16-29.

\section{Authors bibliography}

Dr Dorothy Newbury-Birch is Lecturer in Public Health Research at the Institute of Health and Society, Newcastle University, Newcastle upon Tyne, UK. Katherine Jackson is based at the Institute of Health and Society, Newcastle University, Newcastle upon Tyne, UK.

Tony Hodgson is based at the North East England Team, Youth Justice Board, Leeds, UK.

Professor Eilish Gilvarry is at the Northern Regional Drug and Alcohol Services, Northumbria, Tyne and Wear NHS Trust, Newcastle upon Tyne, UK.

Dr Paul Cassidy is at the Teams Family Practice, Gateshead, UK.

Professor Simon Coulton is at the Centre for Health Services Studies, University of Kent, Canterbury, UK.

Vicky Ryan, Dr Graeme B. Wilson, Dr Ruth McGovern and Professor Eileen Kaner are based at the Institute of Health and Society, Newcastle University, Newcastle upon Tyne, UK.

\section{Corresponding author}

Dr Dorothy Newbury-Birch can be contacted at: d.newbury-birch@tees.ac.uk

For instructions on how to order reprints of this article, please visit our website:

www.emeraldgrouppublishing.com/licensing/reprints.htm

Or contact us for further details: permissions@emeraldinsight.com 